\title{
Comparison of a NLOM data assimilation product to direct measurements in the Antarctic Polar Frontal Zone: a case study
}

\author{
M. Losch ${ }^{1}$, R. Schukay ${ }^{2}$, V. Strass ${ }^{1}$, and B. Cisewski ${ }^{1}$ \\ ${ }^{1}$ Alfred-Wegener-Institut für Polar- und Meeresforschung, Bremerhaven, Germany \\ ${ }^{2}$ Universität Bremen, Germany
}

Received: 3 November 2005 - Accepted: 3 February 2006 - Published: 7 March 2006

\begin{abstract}
A comparison of the Naval Research Lab Layered Ocean Model (NLOM) nowcast fields with independent in-situ observations from a cruise in the Polar Frontal Zone of the Atlantic Sector of the Southern Ocean is presented. NLOM sea surface temperature fields can be used to determine the position of fronts and individual eddies, whereas the analyzed sea surface height appears to be out of phase. It is suggested that this dynamical inconsistency is caused by a low data coverage for assimilation at the time of the cruise in combination with the data assimilation technique, that treats sea surface height and sea surface temperature data independently.
\end{abstract}

Keywords. Oceanography: general (Descriptive and regional oceanography; Numerical modeling; Ocean prediction)

\section{Introduction}

Ocean model data assimilation and operational prediction of the mesoscale ocean circulation has reached a state of maturity that allows to make near real-time products publicly available. A few examples are: MODAS (Fox et al., 2002), FOAM (Bell et al., 2000), DIADEM/TOPAZ (http://www. mersea.eu.org), MERCATOR (http://www.mercator-ocean. fr), BLUElink (Oke et al., submitted, (2005) ${ }^{1}$, see also http: //www.marine.csiro.au/bluelink), and the NLOM data assimilation and prediction (Smedstad et al., 2003; Shriver et al., 2005). These products are not only interesting for their primary purpose, military applications, but also for the scientific community, for instance, as a tool to guide research.

Correspondence to: M. Losch

(mlosch@awi-bremerhaven.de)

${ }^{1}$ Oke, P. R., Schiller, A., Griffin, D. A., and Brassington, G. B.: Ensemble Data Assimilation for an Eddy-Resolving Ocean Model, Quart. J. Roy. Meteor. Soc., 2005.
In this note we report a scientific application of an ocean nowcast/forecast product and we point out a few difficulties that arose during our study. Specifically, we had intended to use sea surface height (SSH) and sea surface temperature (SST) nowcasts and forecasts of the $1 / 16^{\circ}$ global Naval Research Lab (NRL) Layered Ocean Model NLOM (Smedstad et al., 2003) to find a stable mesoscale eddy in the Atlantic sector of the Antarctic Polar Frontal Zone (PFZ) for an iron fertilization experiment. However, during the cruise it quickly became clear that the NLOM SSH data was inconsistent with in-situ observations. In the following we describe data sources and the assimilation system in Sect. 2, investigate the inconsistencies in Sect. 3, and offer a plausible explanation in the last section.

\section{Observations and model data}

\subsection{European Iron Fertilization EXperiment: EIFEX}

Based on in-situ measurements by a conductivity-temperature-depth (CTD) sonde and a ship mounted Acoustic Doppler Current Profiler (ADCP) and satellite altimetry, a mesoscale, cyclonic eddy in the South Atlantic with its center near $49^{\circ} 24^{\prime} \mathrm{S}$ and $02^{\circ} 15^{\prime} \mathrm{E}$ was chosen as the experimental site for the European Iron Fertilization Experiment (EIFEX). For the experiment, a patch within the eddy was fertilized with dissolved iron and subsequently the ecosystem response was monitored.

Throughout the experiment both hydrographic and dynamic parameters were measured at CTD stations inside and outside the fertilized patch and along the ship track in a region extending from approximately $1^{\circ} \mathrm{E}$ to $4^{\circ} \mathrm{E}$ and $48^{\circ} \mathrm{S}$ to $51^{\circ} \mathrm{S}$. Many measurements covered the water column down to $500 \mathrm{~m}$ depth. Here, we use measurements spanning the period from 8 February (day 1) to 16 March 2004 (day 38).

Published by Copernicus GmbH on behalf of the European Geosciences Union. 

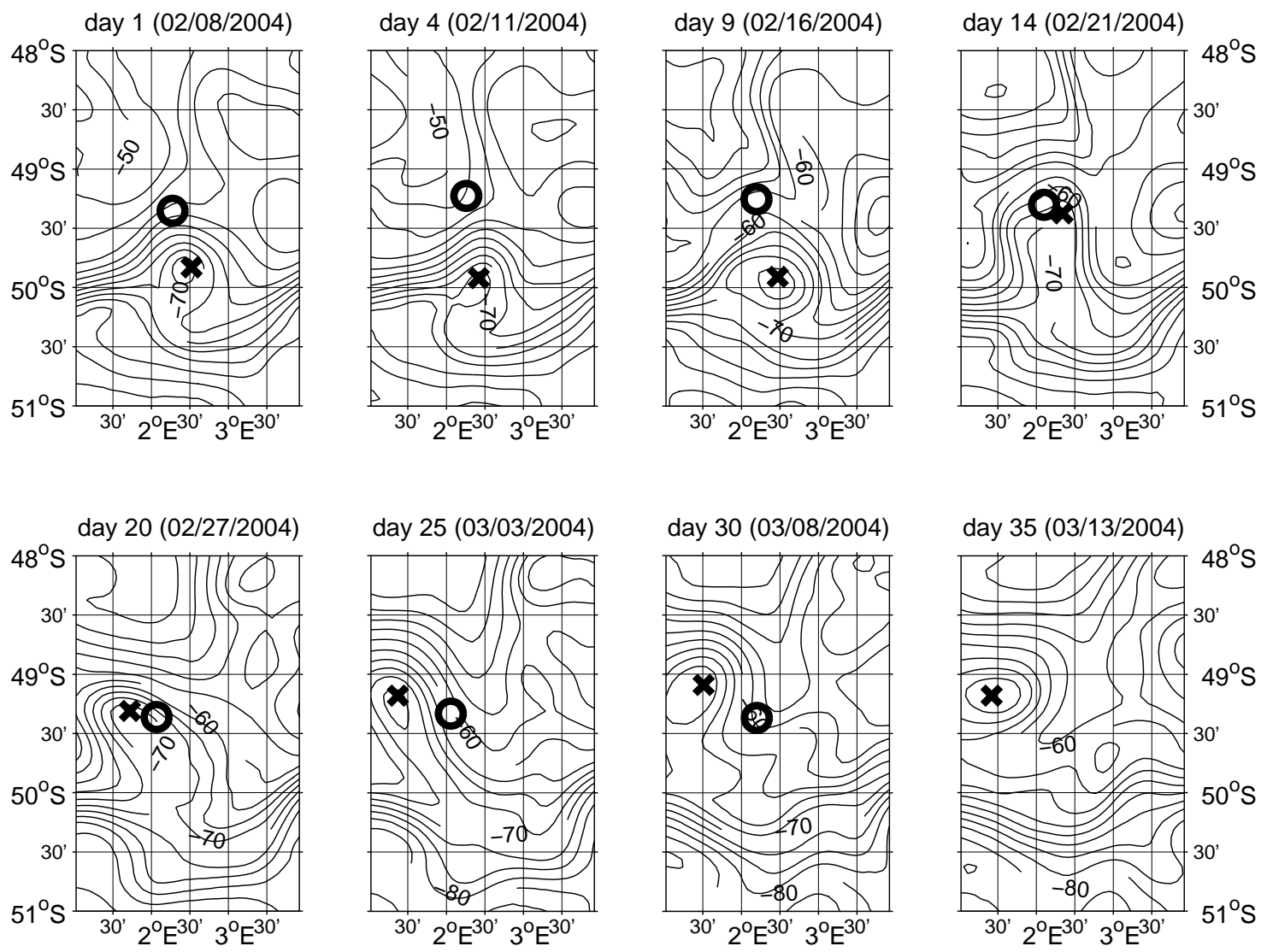

Fig. 1. NLOM SSH, contour interval is $2.5 \mathrm{~cm}$. The circles represent the eddy centers estimated from observed velocities, the crosses the eddy centers from the model velocities. The eddy center on day 35 could not be determined from observations.

Finding a stable eddy was crucial for the success of the experiment, because only such a feature ensures minimal dispersion of the fertilized patch in the highly variable PFZ. Daily satellite altimetry images from http:// ccar.colorado.edu/ $\sim$ realtime/gsfc_global-real-time_ssh/ were used to identify and monitor a suitable eddy both prior to the cruise and during the cruise. The same data source served for posterior comparisons with model and in-situ data. To obtain also forecasts of the future development of the regional eddy field, we tried to use output from a sophisticated data assimilation system that is operated by the Naval Research Laboratory (Smedstad et al., 2003) and is publicly available via the world wide web.

\subsection{NLOM}

The $1 / 16^{\circ}$ global Naval Research Lab (NRL) Layered Ocean Model NLOM is a daily operational product of the Naval Oceanographic Office (NAVOCEANO) with atmospheric forcing from the Navy Operational Global Atmospheric Prediction System (NOGAPS) and assimilation of SST and satellite altimeter data obtained via the NAVOCEANO
Altimeter Data Fusion Center. Both model and data assimilation schemes are described in Smedstad et al. (2003).

The ocean model component is a layered model with six vertical layers and a very high horizontal resolution. SSH data from TOPEX/POSEIDON, its replacement JASON1, Geosat-Follow-On (GFO), and ERS-2 is assimilated using an optimum interpolation (OI) based scheme, a statistical inference technique for vertical mass field updates, and geostrophic balance for velocity updates. The NLOM SST is relaxed to the Modular Ocean Data Assimilation System (MODAS) SST analysis. Real-time and archived results from the model can be viewed at the NRL web site http://www.ocean.nrlssc.navy.mil/global_nlom.

For the duration of the iron fertilization experiment EIFEX, daily nowcasts of SST, SSH, and horizontal velocities in the surface layer were downloaded from ftp:// ftp7300.nrlssc.navy.mil/pub/smedstad/dailyout. (For the period 12-14 February however, there is a gap of 3 days in the time series because of server availability.) 

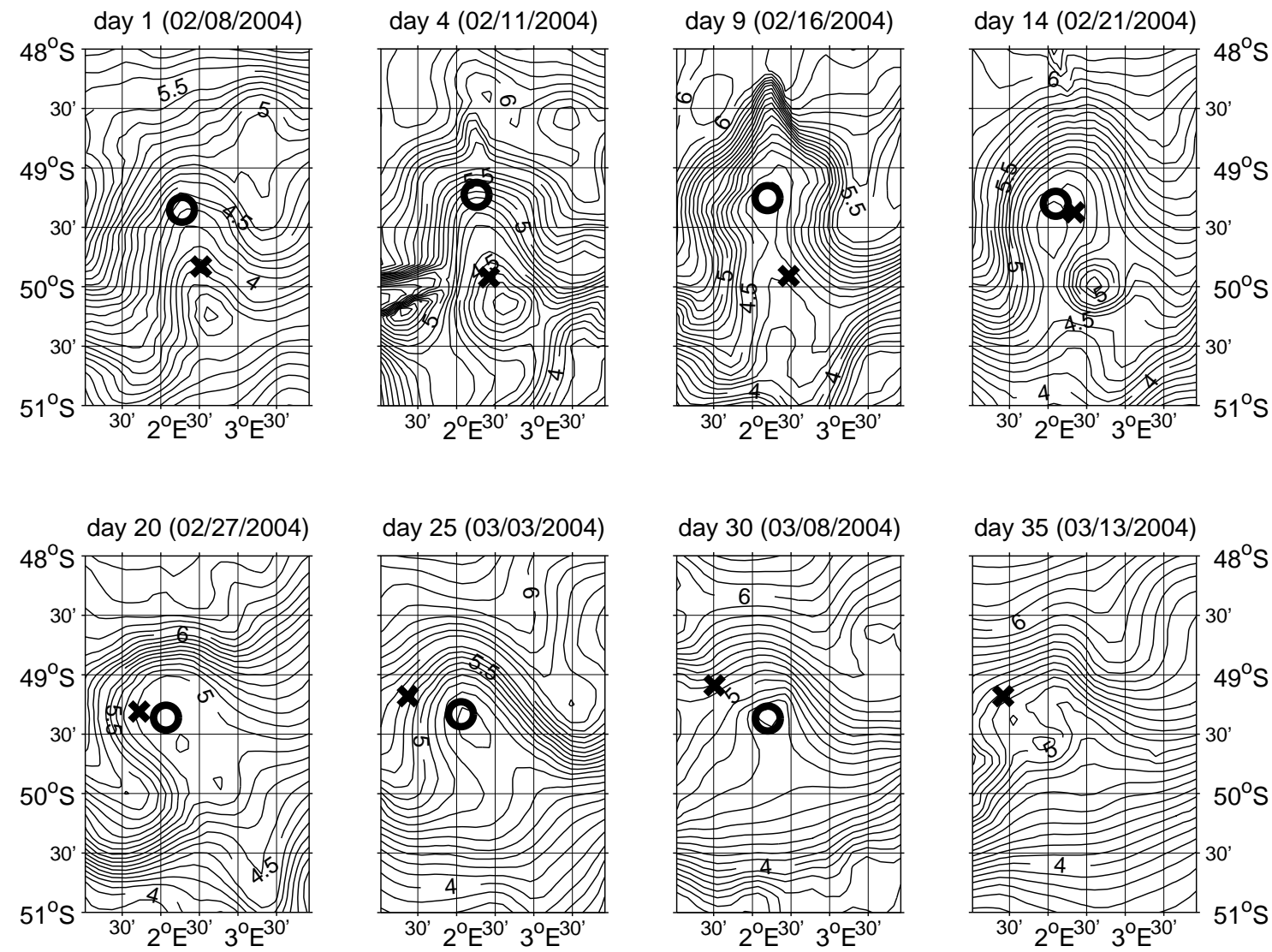

Fig. 2. Same as Figure 1, but for NLOM SST, contour interval is $0.1^{\circ} \mathrm{C}$.

\section{Results}

Figures 1 and 2 show a time series of modeled SSH and SST, respectively. Also shown are the positions of the eddy centers, defined as the point where the horizontal velocities vanish, and estimated separately from both observed ADCP velocities and model data. The modeled SSH pattern agrees with the modeled eddy position, whereas the modeled SST pattern appears to be consistent with the observed eddy position. In order to quantify this impression, we estimate the position of the eddy again from the position of the local minima of SSH and SST separately and determine the distance from the observed eddy centers: The average of this distance is $51 \mathrm{~km}$ for SSH and $30 \mathrm{~km}$ for SST. In other words, modeled SST and SSH pattern appear to be inconsistent with each other in this specific region and time.

NLOM has a limited vertical resolution, so that due to layer-outcropping in the Southern Ocean the top layer in the PFZ may have a thickness of the order of 100 to $200 \mathrm{~m}$ (O. M. Smedstad, personal communication). Therefore the surface layer velocities are compared to vertical averages of the ADCP data that represent the circulation over the top $150 \mathrm{~m}$. For a direct comparison the observed velocities from a centered time window of 5 days are interpolated to

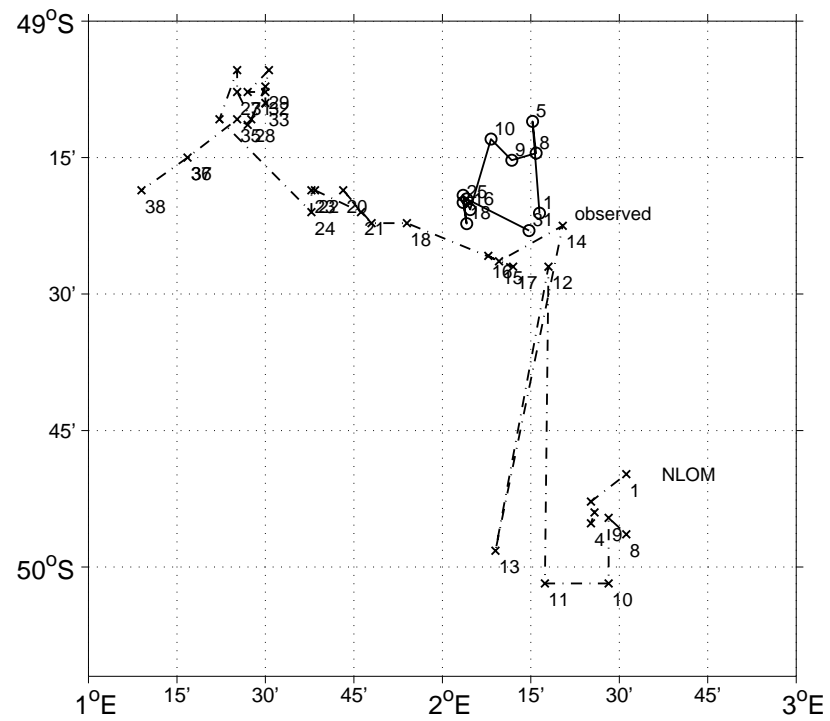

Fig. 3. Displacement of eddy center as estimated from direct velocity observations (circles) and model data (crosses). The annotations refer to the experiment day. Day 1 is 8 February 2004. 
the NLOM model grid. Day 1 corresponds to 8 February 2004. The correlation between modeled and observed velocities is low for days 3 and 9 with coefficients of determination (square of correlation coefficients) of $r^{2}=-0.06$ and $r^{2}=0.13$, respectively and higher for days $12\left(r^{2}=0.44\right)$ and $15\left(r^{2}=0.67\right)$.

In Fig. 3 the positions of of the observed eddy and of the modeled eddy are shown for each day for which it was possible to estimate them in a unique way from the velocity fields. The observed eddy center remains nearly stationary (the maximum displacement is $24.8 \mathrm{~km}$ ), while the eddy of the NLOM model moves through the domain from the southeast corner to the northwest corner covering a distance of $114.5 \mathrm{~km}$ in 38 days. For a few days (day 12, to 18, that is, 19-25 February, except for day 13, which appears to be an outlier), the modeled eddy positions almost coincide with the observed positions, possibly by chance, as the modeled eddy passes the position of the observed eddy.

This explains why the modeled velocity field agrees better with observations on days 12 and 15 than on days 3 and 9 .

An independent estimate of the eddy's position is obtained from the daily satellite altimetry images available at http:// ccar.colorado.edu/ realtime/gsfc_global-real-time_ssh/: The local minimum of the sea level anomaly agrees with in-situ observations (not shown).

\section{Discussion and Conclusion}

NLOM SST data describes consistently the mesoscale pattern in the PFZ for the duration of the EIFEX cruise. Because of the low vertical resolution in NLOM, all but one layer outcrop south of the PFZ, making the model largely barotropic (H. Hurlburt, personal communications). It is reassuring to see that the model still has some skill just north of this area. However, we found that modeled SSH was not consistent with observations. At the same time modeled SST and SSH appear to be inconsistent with each other pointing towards a deficiency in the assimilation scheme.

A close inspection of the available satellite data suggests a possible reason for the discrepancy between model and observations. Satellite altimetry data are essential to keep the almost entirely non-deterministic features and eddies of the model on track. From the end of February to the end of March (i.e. during EIFEX) only a few satellite altimetry data were available: ERS-2 data were only available in the northeast Atlantic, JASON-1 had data outages 15-20 February and 24-26 February, and GFO data were only available until 23 February (see http://www7320.nrlssc.navy.mil/global_ nlom/globalnlom/navo/arc_list_SATELLITES.html). Also satellite altimetry is not assimilated south of $50^{\circ} \mathrm{S}$ by choice (O. M. Smedstad, personal communication), so that part of the EIFEX experimental region did not "feel" any direct effect of SSH assimilation. However, data outages alone cannot explain all differences between in-situ data and model product. For example, Fig. 3 suggests that the NLOM eddy center does not coincide with the observed position of the eddy before 15 February. During the first data outage the NLOM eddy moves even closer to the observed position.

In NLOM, SST and SSH are assimilated separately and with different methods (relaxation for SST with a short $e$-folding scale of $3 \mathrm{~h}$ and an incremental updating technique for SSH), so that in principle, model SST and SSH need not be dynamically consistent immediately after the analysis step. A (more expensive) multivariate data assimilation scheme could improve this situation. In general, observed SSH anomalies and observed SST fields can be expected to have consistent patterns. However, if SSH data are sparse and predominantly SST observations are assimilated, as in the described case, the model may adjust SST quickly, but SSH correction may take a few model hours, resulting in persistently dynamically inconsistent SST and SSH fields. Therefore, we recommend the concurrent use of all (SSH, SST, and velocity) fields of the NLOM product. This procedure avoids the misinterpretation of individual fields that may be temporarily dynamically inconsistent due to a combination of data availability and assimilation technique.

The NLOM assimilation system has been highly successful in many regions of the ocean and model validation tests are impressive (Smedstad et al., 2003; Shriver et al., 2005). However, we found an example of the limitations of the system, mostly determined by its specific data assimilation scheme in combination with poor data availablity. In spite of the enormous progress that has been made over the last decade, optimal data assimilation techniques still require large computer resources and a lot of manpower. Many challenges remain for the future.

Acknowledgements. We thank the Naval Research Laboratory for making the NLOM data publicly available. Fruitful discussions with and numerous helpful comments from O. M. Smedstad and Harley E. Hurlburt are greatly appreciated.

Topical Editor N. Pinardi thanks a referee for her/his help in evaluating this paper.

\section{References}

Bell, M. J., Forbes, R. M., and Hines, A.: Assessment of the FOAM Global Data Assimilation System for Real-Time Ocean Forecasting, J. Mar. Sys., 25, 1-22, 2000.

Fox, D. N., Teague, W. J., Barron, C. N., Carnes, M. R., and Lee, C. M.: The Modular Ocean Data Assimilation System (MODAS), J. Atmos. Oceanic Technol., 19, 240-252, 2002.

Shriver, J. F., Hurlburt, H. E., Smedstad, O. M., Wallcraft, A. J., and Rhodes, R. C.: $1 / 32^{\circ}$ real-time global ocean prediction and value-added over $1 / 16^{\circ}$ resolution, J. Mar. Sys., accepted, 2005.

Smedstad, O. M., Hurlburt, H. E., Metzger, E. J., Rhodes, R. C., Shriver, J. F., Wallcraft, A. J., and Kara, A. B.: A real-time 1/16 ${ }^{\circ}$ global ocean nowcast/forecast system., J. Mar. Sys., 40-41, 341361, 2003. 